\title{
Commentary
}

\section{Linking business schools and practice in direct marketing: Are we missing an opportunity?}

Received: 1st May, 2003

\begin{abstract}
Alan Tapp
is Senior Lecturer in Marketing at Bristol Business School. Alan has published over 35 articles in leading journals and international conferences as well as a best-selling text book. Much of his research has been sponsored by organisations, for example IBM, Christian Dior and The Chartered Institute of Marketing. He is on the Editorial Board of the Journal of Database Marketing \& Customer Strategy Management. He has undertaken research, consultancy and training for organisations as diverse as the NSPCC, The Institute of Direct Marketing, National Centre for Educational Technology, Business Strategies Ltd, The Royal Mail, The CIM, IBM and Coventry City Football Club. He is the author of 'Principles of direct and database marketing', now in its second edition.
\end{abstract}

\section{INTRODUCTION}

Ask a direct marketer at a party what they do and to avoid the opprobrium of junk mail accusations they will probably mutter about interactive marketing or something vague. Asking a marketing academic from a business school the same question leads to equal confusion - 'lecturer', they will say. 'Oh, right', comes the reply. 'How is teaching these days?'

For many academics this is rather missing the point. It may not be widely understood but most academic marketers will have a research requirement written into their jobs, while for many it is their major responsibility. It may be a surprise to some practitioners that there are now over 1,000 academic marketers in business schools in the UK, writing and publishing in dozens of journals. Interestingly, many academic marketing

\section{Alan Tapp}

Bristol Business School, University of the West of England, Frenchay Campus, Coldharbour Lane, Bristol BS16 1QY, UK.

Tel: +44 (0)117 344 3439; e-mail: alan.tapp@uwe.ac.uk researchers are under increasing pressure to get closer to commercial practice. Within academia, direct and database marketing is slowly building a reputation as more than a 'Cinderella' subject. Led by a few schools, notably Bristol Business
School, Cranfield, University of East Anglia and Surrey, academic interest in the subject has been fuelled by the links of direct and database marketing with relationship marketing and, latterly, customer relationship management (CRM).

All of which suggests an increased opportunity for commercial-academic joint projects that will lead to closer working and new knowledge creation. Yet most of the time it is as if managers and academics are on different planets. Both sides seem to occupy a world of their own, barely even acknowledging that the other side exists, let alone that they share many common outcomes.

In this paper the author makes the case for the two sides to work together better, then explores the problems that lie behind the lack of cooperation, before finally proposing a process for closer working to the benefit of both sides.

\section{THE NEED FOR CLOSER WORKING} In the space of a few short years, direct and database marketing (DM) have gone 
from small, specialised niche activities practised by mail order firms to being big players in today's marketing mix. The IT-led CRM 'revolution' has catapulted DM into the big league of spending, with unprecedented senior management focus falling upon the area.

The role of research (either commercial or academic) in direct marketing has not, however, kept pace with these developments. There has never been a strong culture of market research in direct marketing, the discipline instead relying on testing campaign elements in small-scale trials to see what works best. The criticism of direct marketers that they are rarely exercised by the answer to the question 'why' still seems to hold true against many in the sector.

A direct marketing manager looking for help in planning a way through the complexities could consider partnering with marketing academics. What can marketing academics offer? To start with, independent critical thinking and a thorough approach to research. They examine current literature to see what has already been said about the problem at hand. They deploy a range of research techniques to create new knowledge. And they can widen the context within which problems are examined, for instance looking at psychological or sociological insights into consumer problems. It has to be admitted that many commercial partners will find universities initially attractive as providers of independent endorsement of a claim made. This fuels the initial attraction. But it is the genuine value added by academics in adding insight that fuels commitment over a long period.

What are the benefits of commercial partnerships to academics? Business school lecturers committed to applied research will thrive on close exposure to current practice, to see at first hand what is happening where 'the tyre hits the road' instead of second guessing.

Given the clear benefits of collaboration to both parties, why are examples of such collaboration so few and far between? It is worthwhile expanding on just why there are so few success stories, so that is the focus of the next section. The paper then deploys a useful framework from the knowledge management field to propose a solution.

\section{WHAT PREVENTS COLLABORATION?}

There are problems on both sides of the academic-practice divide.

\section{Academic ways of working}

Somewhat ironically, marketing academics have largely got out of the habit of writing to an audience. Customers of their work? In fact, academics largely write to each other, creating a sometimes over-cosy closed user group. The Journal of Database Marketing \& Customer Strategy Management is exceptional in having practitioner input and readership. By and large, marketing managers have never even heard of academics' journals, let alone read them. ${ }^{1}$

There are two problems: relevance and communication. First, relevance. Academics are driven by university league tables and pecking orders, that are determined, partly, by the Research Assessment Exercise (RAE). The RAE is rooted in establishment-created notions of what 'proper', 'excellent' research is. In marketing, this agenda is set by American journals that place 'scientific' research at the top of the pile. The point is that faced with a choice of say, linking up with IBM to look into CRM in practice, versus, say, testing an obscure part of a theoretical model of relationship 
marketing driven by academic debate, academics are nudged towards the latter if they want to progress to professor in a prestigious university. This is not to imply these choices are hard and fast: some academics choose the 'IBM route' above, but the point is simply that the potential is much greater than the current reality of such collaboration. The peer review system still emphasises methodological soundness, demanding often that additional data are gathered which may add plenty to reliability and validity, but regrettably little or nothing to understanding. All this means time has passed, maybe a year or, often, considerably more between the research and its final resting place. The advantage of this is a calmer atmosphere that allows for a more reflective and maybe a more scholarly approach. At the other extreme, academic papers describing, for example, how the internet impacts on consumer behaviour are probably out of date before they go to press.

Secondly, communication. The author recalls a conversation with the managing director of a large advertising agency: 'No, I don't read your journals. In my experience, academics fail to go that extra yard in communicating their work in a useful way.' This was an accurate observation. In truth, a lot of academic work is potentially useful, but the authors have not taken the trouble to find out enough about practitioner issues to then adjust the analysis and communication of their research so that it is actionable. Academics are often very reluctant to adjust their work to make it more readable, more publicity friendly. Sometimes academic snobbery condemns workers who have the temerity to seek PR for their work. The 'scientific' demand for theory neutral observational language - 'it was then hypothesised that...' - makes academic work difficult to read and often boring. Indeed, only a tiny percentage of academics themselves can make sense of some of the papers written in the 'top journals'. The use of obscure language and mind-boggingly complex techniques that serve only to exclude seem to be celebrated. The result? Marketing managers shake heads and shrug their shoulders when they are asked whether they read academic journals.

\section{Practitioners are not reflective enough}

Going back to the question of what prevents useful working at the moment: what about practitioners' ways of working? Reports suggest that the idea that practitioners are doing fine without help is a fallacy.

Quite aside from the well-known descriptions of marketing in practice as being in a "mid life crisis" and 'critically ill' by The Economist, ${ }^{3}$ in a 2001 CIM-funded study examining contemporary marketing in the UK, Tapp et al. ${ }^{4}$ found marketing managers poorly prepared to adopt leadership roles in preparing businesses for technological changes. Businesses are led by finance, IT and operations rather than marketing departments: in 2001 only 13 out of the FTSE 100 CEOs had a marketing background. Those practitioners who are frustrated with the lack of rigour in marketing will agree with Starkey and Madan $^{5}$ who asked why it is that practitioners will not 'set aside fads and begin to work with fundamentals'. An insight came from Griseri ${ }^{6}$ who complained about the macho attitudes of many business people:

'The mythology that management action and thinking are separated is a tyranny.

Management has become overshadowed by a false and entirely distorting image of the successful businessperson as action oriented rather than thoughtful. Both qualities are 
essential. Managers at the moment throw away a lot of good practice because there is no culture of recording and reflection.'

These problems, on both sides of the academic-practice divide, are a shame because the potential rewards of close partnerships are considerable. The good news is that there are thoughtful and reflective people on both sides who can work at the leading edge of a culture change that would lead to more insightful practice.

\section{A NEW TEMPLATE FOR WORKING TOGETHER}

Those who wish to break down the academic-practice barriers can start by asking what both sides have in common. For this author, at the heart of it is a mutual interest in searching for insights into commercial and business life. This recognition has led to many market research departments renaming themselves Customer Insight Departments. This is a fundamental recognition that business decision makers value insights above everything else; above being objective, above data collection, above classic methodology, even - pause while traditional academics have a heart attack - above validity and reliability.

To generate insights, academics and practitioners need to get together. Academic marketers wishing to learn from and influence practitioners cannot do so acting as disinterested, neutral, separate observers of the 'laboratory' of marketing management. Put simply, academics often just do not get close enough to the 'action' to either uncover significant insights, or indeed to communicate those insights in a helpful way to practitioners.

A sound theoretical foundation for closer working can be obtained from the field of knowledge management. Gibbons et al. $^{7}$ describe two modes of knowledge.

Mode 1 knowledge is the scientific, academic approach to knowledge creation - based on single disciplines, more concerned with theory than practice, with how the world works considered at a theoretical level. Mode 2 knowledge is described as transdisciplinary and is concerned with knowledge as it works in practice in the context of application. Griseri $^{8}$ pointed out these differences: 'Academics hope that their systematic research will lead to a body of established knowledge into which a marketing manager can tap to discover the best way of launching a product, manage relationships and so on. In reality every managerial situation is a new multiplex, a manifold of different aspects, which requires being thought afresh'. So, academic work developed for practitioners needs to be broader - in the sense of being transdisciplinary - but shallower in the sense that complex depth will not cope with the endless new contexts the manager is faced with.

Further help can be obtained from Nonaka and Takeuchi ${ }^{9}$ who suggest that knowledge is created and shared through four processes:

- socialisation or everyday comradeship, that transfers and converts tacit knowledge into other forms of tacit knowledge

- internalisation or translating theory into practice, that transforms explicit knowledge into tacit knowledge

- externalisation or codifying a body of knowledge, that transforms tacit knowledge into explicit knowledge

- combination, that transfers and recombines explicit knowledge with explicit knowledge.

According to Nonaka and Takeuchi, the key to knowledge creation lies in the 
mobilisation and conversion of tacit knowledge, and the most important of the above processes for knowledge creation is socialisation. When commercial partners spend time together, learn together and trust is built up, knowledge is created in the form of a shared mental model, metaphor, analogy or culture. Because socialisation involves acceptance of the beliefs, feelings and emotions of others, it is very difficult to achieve without some form of shared face-to-face experience.

Tacit knowledge is more important than explicit knowledge. Tacit knowledge is the root of knowledge creation. It is the deep, unarticulated, experience-based knowledge that workers create over time and is often the bedrock of competitive advantage. This could be combined with academic knowledge (which may be explicit or tacit) to create new and useful outcomes that combine the two.

If the knowledge is created locally by academics and practitioners working together in the field, it is much more likely to be used. A marketing journal paper that is based on remote research is much less likely to resonate with practitioners. Rynes et al. ${ }^{10}$ offer an explanation: 'because underlying assumptions, values, complexities, and processes are omitted from discussions, research conclusions appear less tentative and conditional than they really are'. The idea that socialisation is the foundation of knowledge generation and transfer is expressed in a different way by Griseri. ${ }^{11}$ For him, the true value of management research lies not so much in its findings, which he feels are not generally valid, but in the mutual process of searching for those findings. These thoughts chime strongly with calls made in commercial market research circles for market researchers to expose their thinking. ${ }^{12}$ Smith and Dexter ${ }^{13}$ endorse socialisation approaches by calling for researchers to reveal their thought processes, warts and all, rather than presenting a post-rationalised, sanitised version of findings.

Getting together is not always easy. Mohrman et al. ${ }^{14}$ found that some practitioners expected to receive definitive answers from the project and from the academics and did not want to invest the time required to build the relationship. In short, practitioners are impatient to cut to the chase. For academics, the first rule is probably to choose one's partners carefully. As the CIM study pointed out, many marketing practitioners are reluctant to embrace an intellectual approach to their work. Sometimes practitioners will only use research when confronted with unexpected change - by which time it is very late in the day. Dealing with small companies often causes problems - managers have insufficient resources either to do the research or use it. The author's own difficulties working with football clubs on their fledgling direct marketing efforts are a case in point. The best partners tend to be those who work in the knowledge economy themselves and are used to research. They have strong commercial interests in developing research that they can use themselves.

\section{CHANGES IN METHODOLOGY}

Working together in the 'messy' melting pot of everyday practice implies changes to methodology in the research process. There are increasing calls in academia for a more relaxed approach to creating knowledge, moving away from replicated survey instruments applied in test conditions, towards participatory enquiry methods such as action research and ethnography. Here is Griseri again: '[Marketing] academics need to move away from research designs that depict an 
independent, observed view of marketing in favour of the reality that many of the best investigative activities are more in the way of interventions than they are observations. ${ }^{15}$

There has been a relative lack of use of case study methodology and single site methods to build theory. The way forward is demonstrated by academics like Nigel Piercy who has enjoyed significant success in influencing practitioners with his approach: prolonged contact, close observation and joint research-consultancy participation (see for example his excellent book ${ }^{16}$ that is full of valuable advice for practitioners). Another pointer to a more relaxed methodological future is provided by commercial market research. Barker et al. ${ }^{17}$ discuss the need for more eclectic approaches: market researchers should feel comfortable 'operating in all slices of the information map'. ${ }^{18}$ This may mean incorporating harder, more scientific, more objective data - say, customer database frequency counts - with softer, anecdotal, qualitative data - for instance a database marketer listening to a few customer calls into the company. A greater reliance may be placed on more sources consisting of 'imperfect evidence'. These changes in the way evidence is handled has led to researchers as bricoleurs, that is, using multiple, different sources of data and looking for ways of fitting together a picture out of the hitherto dispersed fragments. ${ }^{19}$ Studies of CRM in practice could benefit from a mixture of case study data, survey work with customers, in-depth interviews with managers and action research in which learning comes from the implementation of the database system.

\section{CHANGES IN COMMUNICATION}

Closer working could really be sealed by clearer communication. Academics at the moment write to each other - a small, cosy, closed user group that awards prizes to each other each year. Self-serving jargon has developed that effectively excludes outside groups. The first step is to recognise that complex, exclusive language is not a sign of cleverness quite the opposite.

Academics need to find a way of writing that pushes forward the boundaries of knowledge while at the same time connecting with the everyday contexts of managers. Pretending that management decisions are made in isolation from wider internal, political or financial factors will get marketers nowhere.

Marketing managers enjoy stories from the marketplace, clearly and simply used to underpin sound principles. The Harvard Business Review deploys exactly these techniques. Marketing managers simply do not relate to the scientific test-the-hypothesis language used in most marketing journals. Indeed, they do not even recognise such work in explaining the reality of their working lives.

\section{CONCLUSION}

What value can academics add in the field of direct and database marketing? The potential is considerable, surely. Issues such as the reality of relationship marketing, the massive spend on CRM IT, social changes and how they affect individualism, new ways of segmenting, bringing together brand building and direct marketing: all these require team-based, multidiscipline, insightful research to move forward. The industry faces many challenges that are common to all - the junk/spam problem, how to best deploy the internet, how to engage with ever more sceptical consumers. In this paper the author has argued that academic-practitioner partnerships that build trust and create knowledge through 
socialisation are the best way forward in solving the challenges above. At the moment there is a misalignment between pure academic work published in academic journals and managers who are not taking up this output. Both sides are poorer as a result.

One template for success may be the author's experience in fostering commercial-academic partnerships. An ongoing 'buy-out' of some of the author's time has been agreed with Harrison Troughton Wunderman in which research projects of mutual interest will be worked on. This will lead to flagship, publicity-friendly research that will position the agency as thoughtful and willing to challenge conventional wisdoms. Meanwhile Bristol Business School enjoys close proximity to cutting-edge practice and insights into current problems. A sign of things to come? Let us hope so.

\section{References}

1 McKenzie, C. J., Wright, S., Ball, D. F. and Baron, P. J. (2002) 'The publications of marketing faculty - who are we really talking to?', European Journal of Marketing, Vol. 36, No. $11 / 12$.

2 Brady, J. and Davis, I. (1993) 'Marketing's mid life crisis', McKinsey Quarterly, No. 2, pp. 17-28.

3 Editorial (1994) 'Death of the brand manager', The Economist, 9th April, pp. 79-80.

4 Tapp, A., Stone, M., Nancarrow, C. and Evans,
M. (2001) 'The impact of e-business on marketing and marketers', report published by CIM, July.

5 Starkey, K. and Madan, P. (2001) 'Bridging the relevance gap: Aligning stakeholders in the future of management research', British Journal of Management, Special Issue 1, Vol. 12, Iss. 4, p. S41.

6 Griseri, P. (2002) 'Management knowledge: A critical view', Palgrave, UK.

7 Gibbons, M., Limoges, L., Nowotny, H., Schwartman, S., Scott, P. and Trow, M. (1994) 'The new production of knowledge. The dynamics of science and research in contemporary societies', Sage, London.

8 Griseri (2002) op. cit.

9 Nonaka, I. and Takeuchi, H. (1995) 'The knowledge-creating company', Oxford University Press, New York.

10 Rynes, S., Bartunek, J. and Daft, R. (2001) 'Across the great divide: Knowledge creation and transfer between practitioners and academics', Academy of Management Journal, Vol. 44, No. 2, p. 340.

11 Griseri (2002) op. cit.

12 Smith, D. and Dexter, A. (2001) 'Whenever I hear the word paradigm I reach for my gun: how to stop talking and start walking', International Journal of Market Research, Vol. 43, Qtr. 3, pp. 321-340.

13 Ibid.

14 Mohrman, S., Gibson, C. and Mohrman Jr., A. (2001) 'Doing research that is useful to practice a model and empirical exploration', Academy of Management Journal, Vol. 44, Iss. 2.

15 Griseri (2002) op. cit.

16 Piercy, N. (1997) 'Market led strategic change', Butterworth Heinemann, UK.

17 Barker, A., Nancarrow, C. and Spackman, N. (2001) 'Informed eclecticism: A research paradigm for the 21st century', International Journal of Market Research, Vol. 43, No. 1, pp. 3-28.

18 Smith and Dexter (2001) op. cit.

19 Barker et al. (2001) op. cit. 